\title{
HISTOCOMPATIBILITY ANTIGENS
}

\author{
CRAIG J. TAYLOR ${ }^{1 \cdot}$ and PHILIP A. DYER ${ }^{2}$ \\ Cambridge and Manchester
}

Keratoplasty is a well-established method for the treatment of irreversible corneal opacity, ocular disease and injury. For primary transplants in patients with avascular corneal beds (usually associated with keratoconus) success rates are relatively high when compared with other forms of organ transplantation, with $90-95 \% 1$ year graft survival. ${ }^{1}$ This is achieved even in the absence of intensive systemic immunosuppression, reflecting the view that the avascular cornea enjoys some degree of 'immunological privilege'. However, even in this situation some $10 \%$ of patients undergo a rejection episode of which up to half may progress to irreversible clouding and graft failure., ${ }^{2,3}$

In contrast, for patients with a vascularised corneal bed a different picture emerges, with $35 \%$ graft loss in the first year following transplantation. ${ }^{4}$ This situation is more closely analogous to solid organ transplants where vascularisation enables access of the host immune system, with a concomitant increased risk of rejection. The most common cause of corneal graft failure remains immunological rejection, particularly within the first six months after transplantation. ${ }^{5,6}$ This group of 'high-risk' patients poses a significant challenge to ophthalmologists, providing an impetus to investigate protocols which will enhance the prognosis.

The proposed immune mechanisms involved in vascularised corneal allograft rejection are both humoral and cellular, similar to those described in kidney and heart transplantation. ${ }^{7-11}$ The involvement of afferent (helper/inducer) and effector (cytotoxic) $\mathrm{T}$ lymphocytes identified in infiltrates during corneal graft rejection implicates similar response mechanisms. Furthermore, animal models have demonstrated that the stimuli governing immunological priming, sensitisation and rejection

From: ${ }^{1}$ Tissue Typing Laboratory, Addenbrooke's NHS Trust, Cambridge; ${ }^{2}$ North West Regional Tissue Typing Laboratory, St Mary's Hos pital, Manchester, UK.

Correspondence to: Craig J. Taylor, Tissue Typing Laboratory, Addenbrooke's NHS Trust, Hills Road, Cambridge CB2 2QQ, UK. are similar for corneal grafts and other forms of allotransplantation. ${ }^{12,13}$

\section{HLA SYSTEM}

The dominant antigenic stimulus for allograft rejection and antibody production is the MHC (major histocompatibility complex). In humans this is known as the HLA (human leucocyte antigen) system. The products of the MHC genes control $\mathrm{T}$ cell antigen recognition. Evidence that HLA is the human MHC came from early kidney transplants performed using related donors. Graft survival was shown to correlate with the number of HLA haplotypes shared between the donor and recipient, with $90 \% 1$ year graft survival between HLA-identical siblings. The $10 \%$ of transplant failures despite immunosuppression, is thought to represent multiple minor histocompatibility antigen differences.

The HLA system is a complex multigene family consisting of more than 10 loci coded for on the short arm of chromosome 6. HLA antigens are codominantly inherited on a maternal and paternal haplotype which are transmitted as a single Mendelian trait. Therefore individuals can express two alleles at each locus. The genes and their corresponding glycoprotein products are divided into two classes based on biochemical and functional properties: HLA class I and class II. ${ }^{14}$

\section{HLA Class I}

HLA class I antigens (HLA-A, -B and -C) are constitutively expressed on virtually all nucleated cells and are referred to as "classical transplantation antigens'. Of particular relevance has been the identification of class I antigens on cells located within all layers of the cornea including the epithelium, stroma and endothelium, ${ }^{15}$ although some reports have been conflicting. ${ }^{16,18}$

Class I antigens consist of a highly polymorphic glycoprotein heavy chain (molecular weight approximately $44 \mathrm{kDa}$ ) with three extracellular immunoglobulin-like domains $(\alpha 1, \alpha 2$ and $\alpha 3)$, a hydrophobic transmembrane region and a cytoplasmic tail. The $\alpha 1$ 
and $\alpha 2$ domains fold to form a peptide binding cleft consisting of eight strands forming an anti-parallel $\beta$ pleated sheet, overlaid by two alpha helices. The cleft 'pockets' which form anchor sites to accommodate nonamer peptides. ${ }^{19}$ The MHC-peptide complexes are stabilised through non-covalent association with beta-2-microglobulin $(\beta 2 \mathrm{~m})$, a non-polymorphic glycoprotein $(12 \mathrm{kDa})$ encoded on chromosome 15. Assembly of the class I heavy chain, $\beta 2 \mathrm{~m}$ and peptide takes place in the endoplasmic reticulum, forming a stable tri-molecular complex which is transported via the Golgi to the plasma membrane. The main areas of polymorphism line the base and sides of the peptide binding groove with the amino acid side chains orientated towards the groove. These side chains influence the topography of the cleft and hence govern the peptide binding repertoire. The ascribed function of HLA class $I$ is for the presentation of endogenous (cytoplasmic) peptides to HLA class I restricted T cells. ${ }^{20}$ The $\alpha 3$ domain is recognised by $\mathrm{CD} 8$-positive $\mathrm{T}$ cells which primarily have cytotoxic (effector) function. ${ }^{21,22}$

HLA-C is expressed at only $10 \%$ of the levels of HLA-A and -B. ${ }^{23}$ Although HLA-C restricted T cells have been generated using virally derived peptides in vitro, it is considered a weak transplantation antigen with no known role in matching for allografts. However, hyperacute rejection of a kidney transplant has been ascribed to HLA-C in a sensitised patient. $^{24}$

The 'non-classical' loci (HLA-E, -F, -G, -H, -I and J) have been recently defined. ${ }^{25}$ Only HLA-E (four alleles) and -G (three alleles) are known to be polymorphic and there is little known about their expression and physiological role. They have no known relevance to clinical transplantation.

\section{HLA Class II}

The HLA class II region consists of three main loci: HLA-DR, -DQ and -DP. The glycoprotein products are non-covalently linked heterodimers each consisting of an alpha chain and beta chain with approximate molecular masses of 33 and $28 \mathrm{kDa}$ respectively. Both chains have two extracellular immunoglobulin-like domains, a transmembrane region and a cytoplasmic tail. The membrane distal domains $(\alpha 1$ and $\beta 1)$ form a peptide binding cleft similar to, but less rigid than, that of HLA class I, accommodating $10 \mathrm{mer}$ to $20 \mathrm{mer}$ peptides.

The $\beta 1$ domains of HLA-DR, -DQ and -DP are extremely polymorphic. In addition, the $\alpha 1$ domain of HLA-DQ is polymorphic, although the alpha chains of HLA-DR and -DP are relatively conserved. HLA class II is constitutively expressed on cells with immune function, required for cooperation with and antigen presentation to helper $\mathrm{T}$ cells. Such cells include B lymphocytes, activated T cells, monocytes, macrophages and dendritic cells. However, expression can also be induced and up-regulated on most cell types during inflammatory responses, mediated by cytokines such as interferon-gamma (IFN $\gamma$ ) and tumour necrosis factor (TNF $\alpha)$. HLA class II expression has been demonstrated within normal corneal epithelium and stromal layers, carried on Langerhans cells and dendritic cells respectively. ${ }^{16,17,26,27}$ These cells are found in high density towards the limbus, although there is a relative paucity within the central cornea. ${ }^{28}$ Induced class II expression has also been reported on all layers of the cornea following in vitro stimulation with IFN $\gamma^{29,30}$ and in vivo during graft rejection and in patients with uveitis. $^{31}$

HLA class II molecules are recognised by CD4positive $T$ cells and are involved in the presentation of exogenous peptides to class II restricted T cells, primarily with afferent helper/inducer functions. ${ }^{21,22,32}$

\section{HISTOCOMPATIBILITY TESTING}

Most HLA typing is performed by serology in a microlymphocytotoxicity assay. This technique uses banks of alloantisera and monoclonal antibodies to define tertiary epitopes and cross reactive groups of HLA glycoproteins on the cell surface. Briefly, $1 \mu \mathrm{l}$ volumes of sera of known HLA specificity are mixed with an equal volume of lymphocytes $\left(2 \times 10^{3}\right.$ cells $)$ in the wells of a microtitre tray. Cell viability is assessed following incubation with rabbit complement and the addition of a vital stain. Currently 23 HLA-A, 48-B, 9-C, 18-DR and 7-DQ antigens can be defined by serology.

In addition, further polymorphism has now been revealed through biochemical and molecular (polymerase chain reaction, PCR) typing techniques which can resolve variants at the DNA sequence level. These procedures can define single amino acid polymorphisms which are indistinguishable by serology. For instance, a total of 97 HLA- DRB1 alleles (the gene encoding the main HLA-DR $\beta$ chain glycoproteins) can be distinguished by molecular typing. PCR typing for class II (HLA-DR, -DQ and -DP) is both rapid and accurate and is now performed routinely in most tissue typing laboratories, with results obtainable within 3 hours. ${ }^{33}$ Currently, optimal HLA typing requires both serological and molecular techniques, as tissue typing of peripheral blood samples from cadaver donors can be difficult. Discrepancy rates of between $10 \%$ and $25 \%$ have been reported for serological HLA-DR typing in kidney transplantation, as revealed by class II DNA typing methods. ${ }^{34,35}$

HLA-DR and -DQ are in strong linkage disequilibrium, with certain alleles occurring together on the same haplotype within particular ethnic groups. ${ }^{36} \mathrm{~A}$ 
positive effect of HLA-DQ matching on renal allograft survival, independent of HLA-DR, has not been proven. ${ }^{37}$ In addition the relevance of molecular subtyping and the role of HLA-DP to solid organ transplant survival has not been resolved.

\section{HLA MATCHING}

\section{Experience in Vascularised Solid Organ Transplantation}

The efficacy of HLA matching for improved graft survival in all forms of solid organ transplantation is controversial. It is known that allograft rejection is primarily mediated by alloreactive $\mathrm{T}$ cells directed against foreign MHC molecules. HLA class II restricted $\mathrm{T}$ helper cells recognise self or non-self peptides in the context of host or foreign MHC and initiate an inflammatory response. ${ }^{38,39}$

Because of the parallels of the rejection mechanisms between corneas and other organs, it is interesting to consider the experience of HLA matching in different tissues. This may serve to indicate relevant factors when considering the value of HLA matching in corneal transplantation. For logistical reasons it is often not possible to match prospectively for heart and liver transplants. Furthermore, the value in terms of improved kidney graft survival has also been questioned. ${ }^{40}$ Demonstration of an HLA matching effect in renal transplantation has relied mainly on large multicentre studies such as the Collaborative Transplant Study (CTS), Eurotransplant and UNOS. ${ }^{41-43}$ Opelz reported a $10 \%$ increase in 1 year first graft survival and a $14-20 \%$ improvement in regraft survival between HLA matched and mismatched transplants. These modest improvements confer greater significance in the longer term, with a twofold difference in the transplant half-life. ${ }^{43,44}$ A consensus of prioritised matching of HLA-DR $>\mathrm{B}>\mathrm{A}$ has proved most significant. ${ }^{45,46}$

Because of an apparent lack of clinical benefit at a local level, many clinicians remain to be convinced of any role of HLA matching and do not consider the prospective selection of donor and recipient pairs worthwhile. Despite clear evidence of the involvement of the MHC in the rejection response, multiple factors may confound any clinical benefit in terms of graft outcome. For example, a diminishing correlation of matching and first graft outcome in kidney transplants has been associated with improved 1 year survival rates using different immunosuppressive regimens. ${ }^{47}$ A strong HLA-DR matching effect was reported for first cadaver grafts in patients immunosuppressed with azathioprine (Aza) and prednisolone (Pred); an intermediate effect when treated with cyclosporin (CyA) either alone or in conjunction with low-dose steroids; and no correlation was found in patients maintained on triple therapy (CyA, Aza and Pred). However in patients on triple therapy (with no difference in graft survival), a marked correlation was observed between HLA-DR matching and clinical course. Mismatched patients suffered more rejection episodes, required increased immunosuppression and longer hospital stays and had higher creatinine levels. Regrafts continued to exhibit a strong HLA-DR matching effect, even on triple therapy.

These results indicate that more effective antirejection therapy can override an HLA matching effect in unsensitised patients. The increased number of rejection episodes in poorly matched grafts are more easily controlled in patients treated with cyclosporin. However, for sensitised patients (particularly regrafts) both the number and magnitude of the rejection response is increased, which cannot be readily controlled by conventional immunosuppressive regimes. Therefore an HLA-DR matching effect is still demonstrable in regrafts.

\section{HLA Matching for Corneal Transplantation}

In view of these observations it is not surprising that HLA matching for corneal transplantation is also controversial. An HLA matching effect may be masked by multiple factors which influence susceptibility to rejection. Such risk factors include the degree of vascularisation (which is often secondary to original diagnosis and graft number), the type and intensity of the immunsuppression used, the mode of storage of the donor corneas, graft size and presensitisation status. ${ }^{3}$

Class I (HLA-A, -B) Matching. Early reports indicating a survival advantage with increased HLA compatibility were comprised of retrospective studies which were often restricted by small numbers, limited definition of HLA alleles and a lack of wellmatched patients. Risk factors such as vascularisation were not always considered independently.

While some reports failed to demonstrate a correlation with graft survival, ${ }^{48,49}$ others were suggestive that increased HLA matching was associated with improved outcome. ${ }^{50-58}$ Early retrospective studies by Gibbs et al. ${ }^{55}$ and Ehlers and Kissmeyer-Nielson ${ }^{56}$ found that compatibility of two or more HLA-A and -B alleles was associated with a decreased risk of graft loss due to rejection in vascularised patients. Batchelor et al. ${ }^{59}$ in a study of 100 cases with severely vascularised corneal beds, reported a stepwise increase in 1 year survival of $38 \%, 43 \%$ and $74 \%$ with 0,1 and 2 HLA-A and -B matches respectively. However, by modern standards this report would be criticised as overall graft survival was only $33 \%$ at 1 year. In a follow-up study from the same centre, Casey and Mayer 60 continued to demonstrate a significant correlation. In this retrospective analysis of 450 HLA-A, B typed 
transplants, avascular grafts did well regardless of the degree of HLA compatibility, whereas those with mild and moderate vascularisation had $76 \% 1$ year survival when zero or one HLA-A, B antigens were shared, compared with $92 \%$ with two or three antigens shared. This demonstrated a clear survival advantage in a cohort of patients at increased risk of rejection, despite overall good survival.

Several studies supported this notion. ${ }^{61-64}$ Of particular note are the data from the Dutch group of 1800 consecutive corneal transplants performed in a single centre. ${ }^{65-70}$ A positive correlation of class I matching was observed in their initial retrospective reports ${ }^{65,66}$ and in later studies with prospectively HLA matched pairs. ${ }^{67-70}$ Interestingly they found the strongest correlation was in the non-' $\mathrm{O}$ ' blood group patients, an observation that has parallels in kidney transplantation. ${ }^{71}$ A surprising observation was a beneficial matching effect in all risk categories, a finding also supported by Boisjoly et al. ${ }^{72}$ Long-term follow-up of the Dutch high-risk patients revealed an $80 \% 15$ year graft survival with two or more antigens matched compared with $55 \%$ with fewer than two antigens matched. ${ }^{73}$

Boisjoly et $a .^{72}$ performed a covariate regression analysis of 435 transplants and found that low risk (avascular) recipients of a class I incompatible small graft were twice as likely to suffer an endothelial allograft reaction. However, applicability of HLA matching to low-risk patients has not generally been confirmed.

Although these reports strongly suggest that minimising HLA incompatibility confers a survival advantage, the main drawback is the predominantly retrospective nature of the studies, with some drawing on historical information for comparison. To address this issue the Collaborative Corneal Transplant Study (CCTS) initiated a double-masked controlled trial to examine the role of prospective matching in an otherwise standardised protocol ${ }^{74}$ Multivariate analysis of 419 high-risk transplants (>2 quadrants vascularised and/or a previously rejected graft) found no difference in outcome or graft reaction between highly matched (zero or one HLA-A, B mismatch) and low matched (two or more mismatched) transplants. The authors attributed the lack of an HLA matching effect and overall high survival ( $65 \%$ at 3 years) to the more intensive and standardised post-operative topical immunosuppressive regimen, abrogating the influence of histocompatibility. A significant survival advantage was, however, found with blood group compatibility, a factor which was previously thought to have little or no relevance. ${ }^{59}$

Class II (HLA-DR) Matching. HLA-DR is considered to be the most influential locus for renal transplants, exerting its effect on kidney transplant outcome within the first 6 months. ${ }^{42,75}$ Analysis of HLA-DR matching for cornea transplantation has provided mixed results. Difficulties in the interpretation of results arise as HLA-DR has not always been considered independently of class $\mathrm{I}^{76,77}$

Hoffmann et $a l .^{78}$ reported a reduced incidence of rejection in HLA-B and -DR matched high-risk patients. Initial reports following retrospective analysis of the Dutch series failed to demonstrate an influence of HLA-DR compatibility. ${ }^{69}$ However, later studies from the same centre reported a positive correlation, with $90 \% 2$ year success for HLA-DR matched corneas compared with $52 \%$ when mismatched. ${ }^{73}$

Similar findings were reported in high-risk cases by Baggesen et al. ${ }^{79}$ using organ cultured corneas which were prospectively matched for HLA-DR by molecular typing (restriction fragment length polymorphism, RFLP). Grafts compatible for HLA-DR had a $93 \%$ survival at 18 months compared with $50 \%$ in a historical control group (fulfilling the same inclusion criteria). This finding was not confirmed by the CCTS, which, as for HLA class I, found no effect of HLA-DR compatibility. ${ }^{74}$

However, caution should be exercised in the interpretation of serological HLA-DR typing results, as tissue typing of post-mortem peripheral blood samples by serology is prone to error. In the United Kingdom, class II typing for kidney transplantation is now performed predominantly by PCR, which is both rapid and accurate. Indeed, the CCTS noted a high number of cases in which only one HLA-DR allele was assigned. This high degree of homozygosity indicated a problem with tissue typing quality. When considering only transplant pairs with four HLA-DR alleles assigned, the relative risk for DR mismatched transplants increased to 1.68 $(p=0.02)$ for graft reaction and $1.6(p=0.07)$ for graft failure. ${ }^{74}$ Therefore, the conclusion that HLADR matching is unimportant may be premature.

\section{What Should We Believe?}

A recent report by Vail et al. ${ }^{80}$ on behalf of the Corneal Transplant Follow-up Study may go some way to resolving the controversy. Multifactorial analysis of prospectively tissue typed grafts found an increased risk of rejection when HLA-A and -B were mismatched, supporting the view that compatibility for class $\mathrm{I}$ is beneficial (relative risk 1.27 per mismatch). However, they observed an inverse correlation for HLA-DR. Incompatible grafts had superior survival compared with matched grafts (relative risk 0.58 per DR mismatch). The possible mechanisms for this apparent paradox are discussed in more detail by Batchelor and Armitage in this issue.

The design of many HLA matching studies has been based on the a priori hypothesis that HLA-DR 
compatibility is most important, as is the case for renal transplantation. Re-analysis of the CCTS data found that when considering only HLA-DR mismatched transplants, there was indeed a positive class I matching effect. HLA-A, -B matched but -DR mismatched transplants had the lowest failure rate of $31 \%$ at 3 years, compared with $41 \%$ when HLA-A, $\mathrm{B}$ and -DR were mismatched. ${ }^{74}$ Although caution is required, this interpretation supports the Bristol data, demonstrating a beneficial effect of class I matching in the absence of HLA-DR compatibility.

\section{CONCLUSION}

A degree of complacency exists about the 'excellent' results of corneal transplantation. However, for a significant minority of patients at increased risk of rejection, graft survival of $50 \%$ at 5 years is below that of kidneys, hearts and livers. Clearly, systemic immunosuppressive protocols which are justified in life-threatening disorders, can not be applied routinely. Therefore the question of tissue matching should be considered further.

Whilst it is difficult to draw firm conclusions from such a diverse range of publications, there are a large number of retrospective and prospective studies indicating that HLA class I matching confers a survival advantage in high-risk cases. Whether this can be overridden by immunosuppressive protocols, as indicated by the CCTS, and what the long-term implications of such a regimen are, remain unanswered.

The data on the relevance of HLA-DR are more ambiguous. A possible inverse relationship of HLADR matching and graft survival has parallels in liver transplantation. Compatibility for HLA-DR may facilitate indirect presentation of donor major or minor histocompatibility antigens to host $\mathrm{T}$ cells, therefore initiating a rejection response. ${ }^{81}$ Study designs, possibly based on an erroneous hypothesis, may have complicated the issue. Factors such as tissue compatibility (or even incompatibility!) may still be important in the longer term.

The main disincentive to HLA matching has been the high degree of polymorphism and the cost. However, most studies indicate that matching for only two or more class I alleles is sufficient to exert a beneficial influence. Furthermore, the cost is less prohibitive if the tissue typing is carried out in parallel with other organ transplant programmes. Clinicians will have to decide on the relative merits of histocompatibility and long-term immunosuppression according to available resources and individual clinical circumstances.

The authors wish to thank Professor Ben Bradley and Dr John Armitage for interesting discussion and the provision of data from the Corneal Transplant Follow-up Study.

\section{REFERENCES}

1. Coster DJ. Dermot Pierse Lecture. Mechanisms of corneal graft failure: the erosion of corneal privilege. Eye 1989;2:251-62.

2. Fine $\mathbf{M}$. The role of corneal vascularisation in human corneal graft reactions. In: Porter R, Knight J, editors. Corneal graft failure. Ciba Foundation Symposium 15. Amsterdam: Associated Scientific Publishers, 1973: 193-204.

3. Boisjoly HM, Bernard PM, Dube I, Laughrea PA, Bazin R, Bernier J. Effects of factors unrelated to tissue matching on corneal transplant endothelial rejection. Am J Ophthalmol 1989;107:647-54.

4. Holland EJ, Olsen TW. Immunosuppression in high risk corneal transplantation. In: Brightbill FS, editor. Corneal surgery: theory, technique and tissue. 2nd ed. St Louis, MO: Mosby-Year Book, 1993:260-8.

5. Williams KA, Sawyer MA, White MA, Mahmood MI, Coster DJ. Report from the Australian Corneal Graft Registry. Transplant Proc 1989;21:3142-4.

6. Kirkness CM, Ezra E, Rice NSC, Steele ADM. The success and survival of repeat corneal grafts. Eye 1990;4:58-64.

7. Stark WJ, Opelz G, Newsome D, Brown R, Yankee R, Terasaki PI. Sensitisation to human lymphocyte antigens by corneal transplantation. Invest Ophthalmol 1973;9:639-45.

8. Ehlers N, Olsen T, Johnsen HE. Corneal graft rejection probably mediated by antibodies. Acta Ophthalmol (Copenh) 1981;59:119-25.

9. Binder PS, Chandler JW, Kaufman HE. In vitro demonstration of cytotoxic antibodies and their possible role in corneal graft rejections. Invest Ophthalmol 1976;15:481-4.

10. Roy R, Wagner E, Boisjoly HM. Role of lymphocytotoxic antibodies in human corneal graft rejection. In: Tsuji K, Aizawa M, Sasazuki T, editors. HLA 1991. Proceedings of the Eleventh International Histocompatibility Workshop and Conference, Vol 2. Oxford: Oxford University Press, 1991:480-2.

11. Jager MJ, Völker-Dieben HJ, Vos A, Broersma L, Kok FG, van der Gaag R. Cellular and humoral anticorneal immune response in corneal transplantation. Arch Ophthalmol 1991;109:972-7.

12. Maumenee AE. Clinical aspects of the homograft reaction. Invest Ophthalmol Vis Sci 1962;1:244-52.

13. Polack FM, Kanai A. Electron microscope studies of graft endothelium in corneal graft rejection. Am J Ophthalmol 1972;73:711-7.

14. Campbell RD, Trowsdale J. Map of the human MHC. Immunol Today 1993;14:349-52.

15. Treseler PA, Foulks GN, Sanfilippo F. The expression of HLA antigens by cells in the human cornea. Am J Ophthalmol 1984;98:763-72.

16. Whitsett CF, Stulting RD. The distribution of HLA antigens on human corneal tissue. Invest Ophthalmol Vis Sci 1984;25:519-24.

17. Mayer DJ, Daar AS, Casey TA, Fabre JW. Localisation of HLA-A,B,C and HLA-DR antigens in the human cornea: practical significance for grafting technique and HLA typing. Transplant Proc 1983;15:126-9.

18. Daar AS, Fuggle SV, Fabre JW, Ting A, Morris PJ. The detailed distribution of HLA-A,B,C antigens in normal human organs. Transplantation 1984;38:287-92.

19. Olaf R, Falk K. Naturally-occurring peptide antigens derived from the MHC class-I-restricted processing pathway. Immunol Today 1991;12:447-55.

20. Townsend A, Öhlèm C, Bastin J, Ljunggren HG, Foster L, Karre K. Association of class I major histocompat- 
ibility heavy and light chains induced by viral peptides. Nature 1989;340:443-8.

21. Guagliardi LE, Koppleman B, Blum JS, Marks MS, Cresswell P, Brodsky FM. Co-localisation of molecules involved in antigen processing and presentation in an early endocytic compartment. Nature 1990;343:133-9.

22. Nuchtern JG, Beddison WE, Klausner RD. Class II MHC molecules can use the endogenous pathway of antigen presentation. Nature 1990;343:74-6.

23. Bunce M, Welsh KI. Rapid DNA typing for HLA-C using sequence-specific primers (PCR-SSP): identification of serological and non-serologically defined HLA$\mathrm{C}$ alleles including several new alleles. Tissue Antigens 1994;43:7-17.

24. Chapman JR, Taylor CJ, Ting A, Morris PJ. Hyperacute rejection of a renal allograft in the presence of anti HLA-Cw5 antibody. Transplantation 1986;42:91-3.

25. Bodmer JG, Marsh SGE, Albert ED, Bodmer WF, Dupont B, Erlich HA, et al. Nomenclature for factors of the HLA system, 1991. Tissue antigens 1992; 39:161-73.

26. Daar AS, Fuggle SV, Fabre JW, Ting A, Morris PJ. The detailed distribution of MHC Class II antigens in normal human organs. Transplantation 1984;38:293-8.

27. Streilein J, Bergstresser PR. Ia antigens and epidermal Langerhans cells. Transplantation 1980;30:319-23.

28. Rodriques MM, Rowden G, Hackett J, Bakos I. Langerhans cells in the normal conjunctiva and peripheral cornea of selected species. Invest Ophthalmol Vis Sci 1981;21:759-65.

29. Young E, Stark WJ, Prendergast RA. Immunology of corneal allograft rejection: HLA-DR antigens on human corneal cells. Invest Ophthalmol Vis Sci 1985; 26:571-4.

30. Mayer DJ. Induction of Class I and Class II major histocompatibility complex antigens in a rat model of corneal transplantation. Acta XXV Concilium Ophthalmologicum. Proceeding of the XXVth International Congress of Ophthalmology, Rome, 4-10 May 1986. Amsterdam: Kugler and Ghedini, 1987:125-34.

31. Donnelly JJ, Li W, Rockey JH, Prendergast RA. Induction of Class II (Ia) alloantigen expression on corneal endothelium in vivo and in vitro. Invest Ophthalmol Vis Sci 1985;26:575-80.

32. Mellins E, Smith L, Arp B, Cotner T, Celis E, Pious D. Defective processing and presentation of exogenous antigens in mutants with normal HLA class II genes. Nature 1990;343:71-4.

33. Olerup O, Zetterquest H. HLA-DR typing by PCR amplification with sequence specific primers (PCRSSP) in 2 hours: an alternative to serological DR typing in clinical practise including donor-recipient matching in cadaveric renal transplantation. Tissue Antigens 1992;39:225-35.

34. Middleton D, Savage DA, Cullen C, Martin J. Discrepancies in serological tissue typing revealed by DNA techniques. Transplant Int 1988;1:161-4.

35. Mytilineos J, Scherer S, Opelz G. Comparison of RFLP-DR beta and serological HLA-DR typing in 1500 individuals. Transplantation 1990;50:870-3.

36. Taylor CJ. The HLA system and nomenclature. In: Morris PJ, editor. Kidney transplantation: principles and practise. 4th ed. Philadelphia: Saunders, 1993; 542-50.

37. Bushell AR, Higgins RM, Wood KJ, Morris PJ. HLADQ mismatches between donor and recipient in the presence of HLA-DR compatibility do not influence the function or outcome of renal transplants. Hum Immunol 1989;26:179-89.
38. Shoskes DA, Wood KJ. Indirect presentation of MHC antigens in transplantation. Immunol Today 1994; 15:32-8.

39. Lechler RI, Batchelor JR. Restoration of immunogenicity to passenger cell-depleted kidney allografts by the addition of donor strain dendritic cells. J Exp Med 1982;155:31-41.

40. Matas AJ, Frey DJ, Gillingham KJ, Noreen HJ, Reinsmoen NL, Payne WD, et al. The impact of HLA matching on graft survival and on sensitisation after a failed transplant: evidence that failure of poorly matched renal transplants does not result in increased sensitisation. Transplantation 1990;50:599-607.

41. Opelz G, for the Collaborative Transplant Study. How unusual are the University of Minnesota HLA matching results? Transplantation 1992;53:694-6.

42. Thorogood J, Persijn GG, Schreuder GMT, D'Amaro J, Zantvoort FA, van Houwelingen JC, van Rood JJ. The effect of HLA matching on graft survival in separate posttransplantation intervals. Transplantation 1990; 50:146-50.

43. Takemoto S, Terasaki PI, Cecka JM, Cho YW, Gjertson DW, for the UNOS Scientific Renal Transplant Registry. Survival of nationally shared, HLA-matched kidney transplants from cadaveric donors. N Engl J Med 1992;327:834-9.

44. Opelz G, Schwarz V, Engelmann A, Back D, Wilk M, Keppel E. Long-term impact of HLA matching on kidney graft survival in cyclosporine-treated recipients. Transplant Proc 1991;23:373-5.

45. Opelz G. Influence of HLA matching on survival of second kidney transplants in cyclosporin-treated recipients. Transplantation 1989;47:823-7.

46. Dyer PA, Johnson RWG, Martin S, Bakran A, Gokal $\mathrm{R}$, Harris $\mathrm{R}$, et al. Evidence that matching for HLA antigens significantly increases transplant survival in 1001 renal transplant performed in the North West Region of England. Transplantation 1989;48:131-5.

47. Taylor CJ, Welsh KI, Gray CM, Bunce M, Bayne AM, Sutton PA, et al. Clinical and socio-economic benefits of serological HLA-DR matching for renal transplantation over three eras of immunosuppression regimens in a single unit. In: Terasaki PI, Cecka JM, editors. Clinical transplants 1993. Los Angeles, California: UCLA Tissue Typing Laboratory, 1994:233-41.

48. Allansmith MR, Fine M, Payne R. Histocompatibility typing and corneal transplantation. Trans Am Acad Ophthalmol Otol 1974;78:445-60.

49. Ducrey NM, Glauser MP, Frei PC. Corneal transplantation: ABO blood groups and HLA compatibility. Ann Ophthalmol 1980;July:880-4.

50. Ehlers N, Kissmeyer-Nielson F. Influence of histocompatibility antigens on the fate of the corneal transplant. In: Porter, R, Knight J, editors. Corneal graft failure. Ciba Foundation Symposium 15. Amsterdam: Associated Scientific Publishers, 1973:307-22.

51. Gibbs DC, Batchelor JR, Werb A, Schlesinger W, Casey TA. The influence of tissue-type compatibilityon the fate of full thickness corneal grafts. Trans Ophthalmol Soc UK 1974;94:101-26.

52. Vannas S, Karjalainen K, Ruusuvaara A, Tiilikainen A. HLA compatible donor for the prevention of allograft reaction. Graefes Arch Klin Ophthalmol 1976; 198:217-22.

53. Stark WJ, Taylor HR, Bias WB, Maumenee AE. Histocompatibility (HLA) antigens and keratoplasty. Am Ophthalmol 1978;86:595-604.

54. Ruusuvaara P. Histocompatibility and corneal graft 
endothelium. Acta Ophthalmol (Copenh) 1979; $57: 968-81$.

55. Gibbs DC, Batchelor JR, Casey TA, Werb A, Liakos G, Taylor CJ. HLA matching and corneal graft rejection. Doc Ophthalmol Proc Ser 1979;20:139-49.

56. Ehlers N, Kissmeyer-Nielsen F. Corneal transplantation and HLA histocompatibility: a preliminary communication. Acta Ophthalmol (Copenh) 1979;57:738-41.

57. Fronterre A, Trimarchi F, Bo G. HLA antigens and selection of donors in corneal transplants. Curr Ther Res 1980;27:749-56.

58. Özdermir Ö. A prospective study of histocompatibility testing for keratoplasty in high-risk patients. $\mathrm{Br} \mathrm{J}$ Ophthalmol 1986;70:183-6.

59. Batchelor JR, Casey TA, Gibbs DC, Lloyd DF, Werb A, Prasad SS, James A. HLA matching and corneal grafting. 1976;1:551-4.

60. Casey TA, Mayer DJ. The influence of histocompatibility in corneal graft rejection. In: Henkind P, editor. XXIV congress of Ophthalmology. Philadelphia: Lippincott, 1983:1750-4.

61. Foulks GN, Sanfilippo F. Beneficial effects of histocompatibility in high risk corneal transplantation. Am J Ophthalmol 1982;94:622-9.

62. Foulks GN, Sanfilippo FP, Locascio JA, MacQueen JM, Dawson DV. Histocompatibility testing for keratoplasty in high-risk patients. Ophthalmology 1983; 90:239-44.

63. Sanfilippo F, MacQueen JM, Vaughn WK, Foulkes GN. Reduced graft rejection with good HLA-A and -B matching in high-risk corneal transplantation. $\mathbf{N}$ Engl $\mathbf{J}$ Med 1986;315:29-35.

64. Roy R, Boisjoly HM, Dube I, Bernard PM, Desbiens C. Private and public HLA determinant specifities matching in corneal transplantation. Transplant Proc 1989;21:3139-41.

65. Völker-Dieben HJM, Kok-van Alphen CC, Oosterhuis JA, van Dorp G, van Leeuwen A. First experience with HLA matched corneal grafts in high risk cases. Doc Ophthalmol 1977;44:39-48.

66. Völker-Dieben HJ, Kok-van Alphen C, Kruit PJ. Advances and disappointments, indications and restrictions regarding HLA matched corneal grafts in high risk cases. Doc Ophthalmol 1978;46:219-26.

67. Völker-Dieben HJ, Kok-van Alphen CC, Landsbergen G, Persijn GG. The effect of prospective HLA-A and B matching on corneal graft survival. Acta Ophthalmol (Copenh) 1981;60:203-12.

68. Völker-Dieben HJ, D'Amaro J. Corneal transplantation: a single centre experience 1976 to 1988. In: Terasaki PI, editor. Clinical transplants 1988. Los Angeles, California: UCLA Tissue Typing Laboratory 1988:249-61.
69. Völker-Dieben HJ, D'Amaro J, Kruit PJ, de Lange P. Interaction between prognostic factors for corneal allograft survival. Transplant Proc. 1989;21:3135-8.

70. Völker-Dieben HJ. Corneal transplantation: state of the art. Transplant Proc 1989;21:3116-9.

71. D'Amaro J, Hendricks GFJ, Persijn GG, van Rood JJ Influence of sex and ABO blood group on HLA-A, B and DR matching in renal transplantation. Transplant Proc 1985;17:759-60.

72. Boisjoly HM, Roy R, Bernard PM, Dube I, Laughrea PA, Bazin R. Association between corneal allograft reactions and HLA compatibility. Ophthalmology 1990;97:1689-98.

73. D'Amaro J, Völker-Dieben HM, Kruit PI, Pels E, de Lange R, Schipper R. HLA matching and other factors in corneal transplantation: a single-centre experience with more than 1800 consecutive transplants in 15 years. In: Tsuji K, Aizawa M, Sasazuki T, editors. HLA-1991. Proceedings of the Eleventh International Histocompatibility Workshop and Conference, vol. 2. Oxford: Oxford University Press, 1991:478-9.

74. The Collaborative Corneal Transplant Studies (CCTS) Research Group. Effectiveness of histocompatibility matching in high-risk corneal transplantation. Arch Ophthalmol 1992;110:1392-403.

75. Gilks WR, Gore SM, Bradley BA. Renal transplant rejection: transient immunodominance of HLA matches. Transplantation 1990;50:141-6.

76. Boisjoly HM, Roy R, Dube I, Langhrea PA, Michaud R, Douville P, Hebert J. HLA-A, B and DR matching in corneal transplantation. Ophthalmology 1986; 93:1290-7.

77. Beeckhuis WH, van-Rij G, Renardel-de Lavalette JG, Rinkel-van Driel E, Persijn G, D'Amaro J. Corneal graft survival in HLA-A and HLA-B matched transplantations in high-risk cases with retrospective review of HLA-DR compatibility. Cornea 1991; 10:9-12.

78. Hoffmann F, von Keyserlingk HJ, Wiederholt M. Importance of HLA-DR matching for corneal transplantation in high-risk cases. Cornea 1986;5:139-43.

79. Baggesen K, Lamm LU, Ehlers N. Effect of HLA-DR/ RFLP matching in complicated corneal transplantations. In: Terasaki PI, editor. Clinical transplants 1990. Los Angeles, California: UCLA Tissue Typing Laboratory, 1990:197-201.

80. Vail A, Gore SM, Bradley BA, Easty DL, Rogers CA, Armitage WJ, on behalf of the Corneal Transplant Follow-up Study Collaborators. Influence of donor histocompatibility factors on corneal graft outcome. Transplantation; 58:1210-17.

81. Coster DJ. Influences on the development of corneal transplantation. Eye 1994;8:1-11. 